Cad.Est.Ling., Campinas, 50(2):217-230, Jul./Dez. 2008

\title{
AJUNTAMENTO DE FONTES PARAAHISTÓRIADO PORTUGUÊS POPULAR BRASILEIRO: AMORES, DESAMORES E OUTRAS ESPÉCIES DE DORES
}

\author{
KLEBSONOLIVEIRA \\ UFBA-PROHPOR/PRODOC-CAPES
}

\begin{abstract}
Although Popular and Standard Brazilian Portuguese share the same norm continuum, the linguistic reality in Brazil is polarized and plural and the boundaries between them has not been well clarified yet. Thus the work of reconstruction of their history cannot follow the same directions. The history of literacy is a history of few, a history of white men, a history of the flower of society. In this particular case, the archives are usually sufficiently generous. Differently, investigating the Popular Brazilian Portuguese is dealing with record dispersion and, above all, with problems that involve questions related to collecting and editing the poverty of material to be of some usefulness. The present work aims at examining these source problems, starting from the observation of documents written in the scope of a black brotherhood during the nineteenth century in Salvador, painted boards from the eighteenth to the twentieth century, that constitute a sort of votive practical and, finally, letters of "cangaceiros", from the beginning of the twentieth century.
\end{abstract}

\section{PARA INÍCIODE CONVERSA, OU MELHOR,DE LEITURA}

Quando se apresenta, no título deste texto, a expressão Ajuntamento de fontes para a história do português popular brasileiro, terá ela, toda ela, de se vincular ao que se pode designar de produtos gráficos saídos de mãos das classes subalternas que, aqui, referencia blocos de indivíduos pertencentes a classes sociais inferiores que, a princípio e dentro de uma perspectiva histórica, não puderam ou não tiveram a oportunidade de se manifestarem por escrito.

Sabe-se que a história da leitura e da escrita no Brasil é história de poucos: provavelmente de brancos e, mesmo assim, da elite. Amparam a assertiva dessa alínea os dados sobre escolarização: em fins do século XVIII, estava em torno de $0.5 \%$ a $1.0 \%$ o número de letrados no país (Houaiss, 1992[1984], p. 141). O primeiro censo oficial feito para o Brasil, o de 1872, revela que, entre os escravos, o índice de analfabetismo atingia 99.9\% desse contingente mantido em cativeiros; entre a população livre, os números ficam em, aproximadamente, $80.0 \%$, elevando-se para $86.0 \%$ quando se incluem as mulheres. Ainda desvelou o censo mencionado que somente $16.8 \%$ da população entre 6 e 15 anos freqüentavam escolas (Fausto, 1994, p. 237). Em outro censo realizado 18 anos depois, portanto em 1890, as perspectivas também não são das melhores: contando o Brasil com uma população geral em torno de 14.339.915, possuíam a faculdade das letras apenas $14.8 \%$. 
OLIVEIRA - Ajuntamento de fontes para a história...

De frente com o panorama exposto, contendo dados sobre a história da alfabetização no Brasil, emerge a primeira questão a ser problematizada: onde encontrar fontes que podem ser de serventia para uma história do português popular brasileiro? O paleógrafo italiano Amando Petrucci (p. 1999, 29-30) propõe, por assim dizer, um roteiro que abraça seis direções. Consoante o autor, os testemunhos gráficos produzidos pelas classes subalternas ou a elas destinados podem fazer a sua aparição nos seguintes lugares: a) Fundos administrativos públicos, onde se encontram contas ou recibos de trabalhos realizados por artesãos; correspondência de administradores; correspondências militares; b) Fundos judiciais, onde se acham denúncias e materiais de prova incorporados às atas processuais; c) Arquivos privados (administração patrimonial), onde se encontram contas e correspondências de subordinados; d) Arquivos notariais, em que, geralmente, se pode esbarrar com testamentos autógrafos adjuntos; e) Fundos manuscritos de bibliotecas, onde, além da possibilidade de achar material documental do tipo já mencionado, se pode ainda dar de frente com "livrinhos" manuscritos de caráter devocional, narrativo-fantástico, médico (receitas), mágico etc, produzidos diretamente por representantes das classes subalternas e, geralmente, semi-alfabetizadas e f) Grafites ou inscrições estampadas e feitos a carvão em paredes pintadas ou em pórticos de entrada das igrejas e capelas rodeadas por uma devoção particular ou alvo de peregrinações.

Petrucci, contudo, italiano que é, certamente não tem em conta o desenrolar do processo de alfabetização no Brasil e a sua proposta está voltada, sobretudo, para os países europeus de longa tradição escrita e riquíssimos em arquivos a serem explorados. De qualquer sorte, o farol por ele acendido não é de todo descartável e, além do mais, dará o autor idéias bastante proveitosas das quais este texto se apropriará. Uma delas: a busca de materiais escritos pelas classes subalternas ou como expressão da sua vontade intermediada por diálogos. Dito de outro modo, consagra Petrucci (1999, p. 30) a interdisciplinaridade como ingrediente fundamental em qualquer história voltada à escrita. Palavras suas:

O historiador da escrita deverá manter estreitas relações com os historiadores da economia, da demografia, da língua e literatura, com os arquivistas e conservadores de manuscritos de bibliotecas públicas e privadas, com os historiadores do livro e da imprensa.

Deixando-se, por enquanto, as lúcidas idéias de Petrucci (1999), navegar-se-á em universos nos quais, no Brasil, são possíveis os flagrantes de produtos gráficos produzidos por classes subalternas.

\section{ASOCIEDADE PROTETORADOS DESVALIDOS: UMA IRMANDADE DE COR}

Apegando-se ao que disse Petrucci (1999, p. 30) sobre os diálogos que a história da escrita deve manter com outras áreas do conhecimento, destacam-se, para este item, dois deles. O primeiro foi travado com um texto da lingüista Rosa Virgínia Mattos e Silva - Para a história do português culto e popular brasileiro: sugestões para uma pauta de pesquisa - de 2002, e o segundo, com um do historiador João José Reis, intitulado Identidade e 
Cadernos de Estudos Lingüísticos 50(2) - Jul./Dez. 2008

diversidade étnicas nas irmandades no tempo da escravidão, de 1997. Mas o que um tem a ver com o outro? "Devagar com o andor!".

No texto de Mattos e Silva, acima dito, aparece a defesa da autora a favor da hipótese de que, no Brasil passado, foram os africanos e seus descendentes os mais prováveis utentes do português popular brasileiro. Mas esses indivíduos, como demonstram vários estudos de história social, se encontram, via de regra, na base da pirâmide da sociedade, ou seja, parece não haver restrições a enquadrá-los como compósitos de classes sociais subalternas e, deste modo, estariam dentro daquele grupo que não encontraram na escrita um lugar para registrar as suas vozes. Além disso, informação bastante relevante saída do texto de Mattos e Silva (2000, p. 457) diz respeito ao fato de que, para a reconstituição do passado histórico do português popular brasileiro, a via a ser seguida terá de ser indiciária, nos termos em que põe Ginzburg, no seu artigo clássico Sinais: raízes de um paradigma indiciário (1988, p. 143-206). É exatamente aqui que entra em cena o texto de Reis (1997), sobre a história de irmandades negras na Bahia, a desdizer Mattos e Silva (2002).

A criação de irmandades ou confrarias no Brasil foi profícua ao longo do período colonial e pós-colonial. Aqui encontraram terreno fértil e espelharam, na constituição dos seus membros, as tensões de toda natureza que prevaleciam na sociedade. Observem-se as palavras de Reis (1997, p. 12) a respeito do que se conta:

\begin{abstract}
A sociedade formada na colônia escravocrata estava estruturada em moldes corporativistas que refletiam diferenças sociais, raciais e nacionais. As irmandades são um exemplo disso. Muitas fizeram as vezes de corporações profissionais típicas do antigo regime. Algumas poucas abrigavam a nata da sociedade, a 'nobreza' da colônia, os senhores de engenho, altos magistrados, grandes negociantes. Mas o principal critério de identidade dessas organizações foi a cor da pele em combinação com a nacionalidade. Assim, havia irmandades de brancos, de mulatos e de pretos. As de branco podiam ser de portugueses ou de brasileiros. As de preto se subdividiam nas de crioulos e africanos. Estas podiam se fracionar ainda de acordo com as etnias de origem - ou, como se dizia na época, as 'nações' - havendo as de angolanos, benguelas, jejes, nagôs etc.
\end{abstract}

O que interessa para este texto é tudo, ou quase tudo, que se relaciona com as irmandades negras e pertencer a uma delas tinha o seu preço: freqüentemente, exigia-se dos associados uma quantia, designada por jóia, com a qual se davam às órfãs dotes, se hospitalavam os doentes, se visitavam os indigentes, se emprestava dinheiro para alforria, se ofereciam, aos seus membros, enterros decentes nos seus cemitérios etc.

Dada acima a moldura em que se estampavam as irmandades negras, é chegada a hora de subir ao palco a informação mais preciosa fornecida por Reis (1997, p. 12). Segundo o historiador, "os estatutos das confrarias, chamados compromissos, e outros documentos constituem uma das poucas fontes históricas da era escravocrata escritas por negros ou pelo menos como expressão da sua vontade. As irmandades, aliás, produziram muita escrita". De posse da "vara e da isca", a pescaria começou, mas ela se mostrou mais penosa do que se imaginava, na medida em que, pouco a pouco, as irmandades negras foram fechando as suas portas, sobretudo depois da Abolição da Escravatura, e saber o paradeiro da documentação produzida no âmbito dessas instituições é tarefa das mais difíceis de se empreender. 


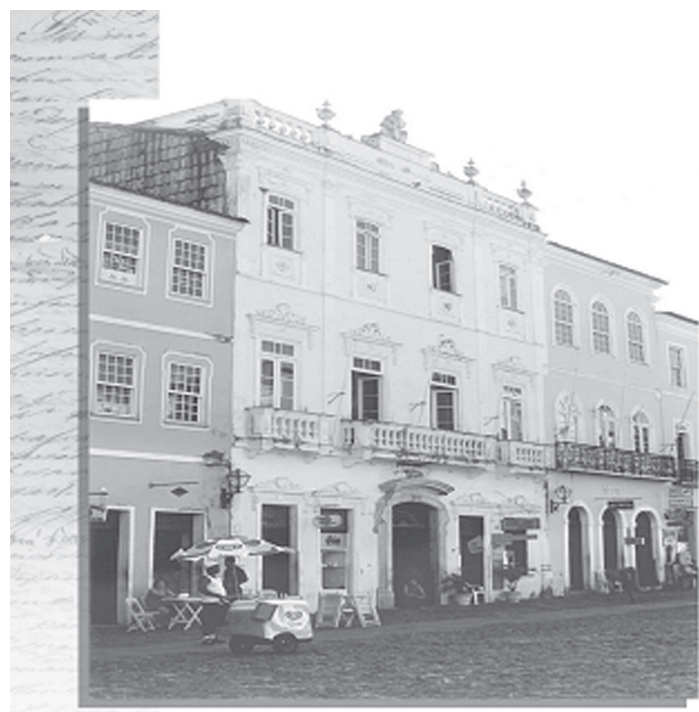

Figura 1: Sociedade Protetora dos Desvalidos Cruzeiro de So Francisco - Salvador/Bahia

As conversas com profissionais de outras áreas, as leituras extensivas sobre o tema, a busca incessante para atingir um propósito e, talvez, uma pitada de sorte fizeram com que se chegasse à Sociedade Protetora dos Desvalidos, doravante também SPD, uma irmandade fundada por homens de cor, africanos, na cidade de Salvador no ano de 1832. Ganha, "de cara”, destaque a SPD por continuar de pé até os tempos que correm, o que possibilitou a conservação de um acervo documental que se circunscreve dentro de um arco temporal que vai de 1832, data da sua fundação, até os dias de hoje. Parte desse acervo, apenas documentos do século XIX, compôs a parte filológica da tese de doutorado de Oliveira

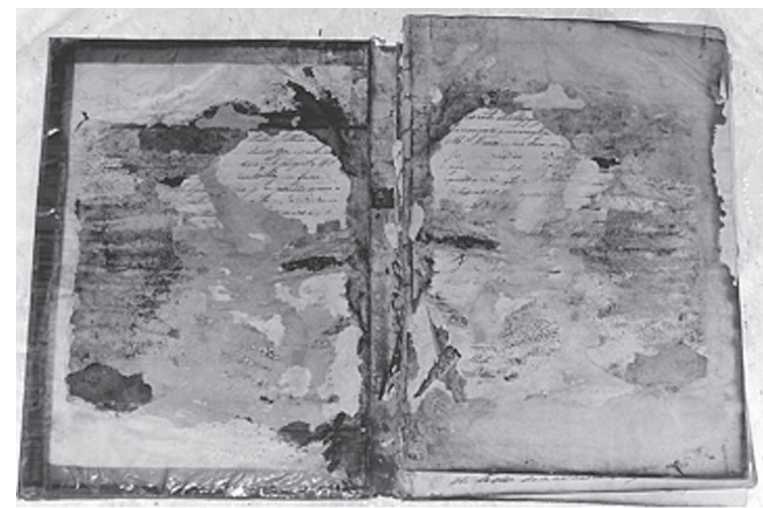

Figura 2: Livro de Termos - 1850

Acervo SPD 
Cadernos de Estudos Lingüísticos 50(2) - Jul./Dez. 2008

(2006). Acontece, no entanto, que a conservação do acervo documental a que se fez referência carece de alguns "poréns".

O primeiro deles alude às péssimas condições em que se encontram os livros em que constam variadas tradições discursivas: atas, circulares, relatórios, livros de contas, livros de requerimentos etc. $\mathrm{O}$ tempo deixou marcas: fortes em alguns livros, fracas em outros; por sorte, resolveu deixar em paz muitos exemplares. É bem-vindo um fato a ilustrar o que se diz: para a feitura da tese de doutorado de Oliveira (2006), estava nos planos representar, na parte referente à edição filológica, documentos de todas as décadas do século XIX, mas a de 50 não pode dar o seu quinhão, porque os livros em que residem os textos da década mencionada não deram nenhuma possibilidade de margem à leitura. Completamente estragados e sem a menor chance de recuperação, não sobrou, para ser lida, uma folhinha sequer para contar a história. E não é só isso: mesmo os livros aparentemente bem conservados exibem em seu interior fólios danificados, seja pela qualidade da tinta utilizada, que está se esvaindo com o devir do tempo, seja porque a tinta se intrometeu no lado oposto do fólio, seja porque os papirófagos se depararam com material para um banquete farto etc, o que exigiu, por parte do editor, um esforço em trazer à tona aquela escrita que, a todo custo, teimava em se manter escondida. Editar documentos com esses desamores é pedir, literalmente, para entrar em uma partida de queda, ou quebra, de braços.

Mas lidar com documentação preservada em acervos de irmandades negras pode fazer com que se esbarre em outro desafeto: é que a escrita dentro dessas instituições caritativas, compostas por homens de cor, nem sempre foi por eles redigida e, sim, por brancos que procuravam delas participar como estratégia de controle, embora, algumas vezes, até o fizessem por devoção sincera. Os negros aceitavam a participação dos brancos por diversos motivos: para que cuidassem dos livros era um deles, uma vez que não tinham instrução para escrever e contar e certos cargos, como o de escrivão e tesoureiro, por exemplo, exigiam as referidas habilidades. Desde modo, é preciso saber, de maneira vertical, a história que cada irmandade carrega sobre si, porque se pode incorrer no risco de atribuir a mãos negras produtos caligráficos executados por mãos brancas. A emergência desse risco, no entanto, parece mais provável de acontecer com irmandades negras cuja fundação antecede os oitocentos, como é o caso, por exemplo, da irmandade de Nossa Senhora do Rosário dos Pretos, tanto em Minas como na Bahia.

\section{OS DESAMORES E OUTRAS ESPÉCIES DE DORES}

Mesmo que vagamente, já deu para sentir que obstáculos é o que não faltam quando se tem a pretensão de ajuntar fontes para a história do português popular brasileiro. Petrucci (1999, p. 29) acerta em cheio quando, no seu artigo, deriva o assunto para os empecilhos encontrados para o estudo de testemunhos gráficos produzidos pelas classes subalternas ou a elas dirigidos. Fala de três deles: a sua raridade, a sua dispersão arquivística e o seu mínimo quociente de durabilidade. Transplantando-os para a realidade brasileira, como podem esses elementos ser configurados? No que diz respeito à raridade, basta que se relembre dos índices referentes à história da alfabetização no Brasil, em que "exclusão" 
OLIVEIRA - Ajuntamento de fontes para a história...

parece ter sido a palavra de ordem. A Sociedade Protetora dos Desvalidos, mesmo que o seu acervo, em alguns momentos, não fizesse nenhuma questão de esconder a sua má vontade com o filólogo, escapou do que Petrucci chamou de dispersão arquivística, mas há exemplos claríssimos, que chegam a cegar, da sua exibição.

Daqui a pouquinho, falar-se-á mais detidamente sobre eles, contudo, para o que se deseja - exemplificar a dispersão arquivística - serão convocados três artigos feitos ou em confecção por Oliveira. O primeiro deles intitula-se E agora, com a escrita, os escravos, de 2004, cujo eixo temático gira em torno de 14 textos produzidos por escravos, de punho próprio ou como expressão de sua vontade. Para a elaboração do texto tiveram de dar a sua contribuição o Arquivo Público do Estado da Bahia, o Arquivo Público do Estado do Piauí e o Arquivo Público do Estado de São Paulo. Já em As tábuas votivas: mais uma fonte para a história do nosso "latim vulgar", no prelo, recorreu-se ao acervo da igreja de Nosso Senhor do Bomfim, na Bahia, do Museu de Arte Sacra de Angra dos Reis, no Rio de Janeiro, do santuário de Nosso Senhor de Matosinhos, em Congonhas do Campo, Minas Gerais, ao catálogo organizado por Castro (1994), com tábuas votivas provenientes de diversas cidades mineiras, e ao acervo particular do antropólogo Luiz Mott. O acervo da Sociedade Brasileira de Estudos do Cangaço, da Associação Cabras de Lampião, do Instituto Histórico e Geográfico de Alagoas e do Arquivo Público do Estado de Alagoas lastrearão o artigo $O$ papel da escrita no circuito do cangaço, ainda em fase de elaboração.

Quanto ao último fator a se configurar quase como um calvário para aqueles que intencionam cavar os produtos gráficos de mãos subalternas, o já referido mínimo quociente de durabilidade, afiança Petrucci $(1999$, p. 29) que está ligado principalmente a dois fatores que assinalam, de forma explícita, a passividade e a ocasionalidade das relações que as classes populares mantêm com a cultura escrita. O primeiro dos fatores toca à escassa durabilidade do produto destinado às classes subalternas, ou seja, para a confecção do livro, do periódico popular, dos instrumentos para a escrita, são utilizados materiais de baixa qualidade e técnicas de pouco custo, o que contribui para que as manifestações gráficas, por conta desse desamparo na esfera do qualitativo, tenham os seus dias contados. Já o segundo motivo se enraíza na ausência de uma mentalidade que comporte o preocuparse com a conservação desses produtos gráficos nos ambientes permissivos à sua emergência. $\mathrm{O}$ acervo preservado na Sociedade Protetora dos Desvalidos já deu mostras de que pode ser emoldurado nesses dois aspectos, porém existem outros lugares de escrita que os abraçam e, ainda por cima, trazem questões que lhes são específicas.

\section{CARTAS DE ESCRAVOS}

Com o propósito de exemplificar o que Petrucci (1999, p. 29) denominou de dispersão arquivística, já se falou, en passant, de 14 cartas de escravos redigidas em vários lugares do Brasil e preservadas em diversos fundos documentais. O ajuntamento desse material só foi possível, sobretudo, por conta de diálogos com profissionais de outras áreas do conhecimento. Historiadores e antropólogos, principalmente, deram fortes contribuições, com destaque para Wissenbach (1998) que brindou a comunidade lingüística, interessada pelo binômio escrita-classes subalternas em perspectiva histórica, com a descoberta de 8 
textos redigidos por indivíduos em cativeiros ou como expressão da sua vontade, no Arquivo Público do Estado de São Paulo e anexos, todos eles, a um processo movido contra os escravos Teodora da Cunha Dias, africana, e Claro Antônio dos Santos, brasileiro.

Wissenbach (1998, p. 265-268) faz a apresentação dos textos referidos numa edição que, a princípio, parece prezar pela fidelidade aos originais. Contudo, como historiadora que é e com a desconfiança de filólogo ao lado, pediuse a reprodução do processo e, de início, uma grata surpresa: conta-se em 10 os textos, portanto 2 a mais e inéditos a darem o seu quinhão para o conhecimento e reconhecimento do português escrito por "mãos algemadas". A intuição se revelou amiga e o cotejo da leitura feita por Wissenbach (1998, p. 265-268) com os originais, já em mãos, apontou para muitos desencontros: saltos-bordões, inversões, omissões, substituições e acréscimos de grafemas, ocultamento de vocábulos, letras minúsculas em lugar de maiúsculas e vice-versa. Apresenta-se, a seguir, as duas leituras efetuadas de uma carta do brasileiro Claro Antônio dos Santos, feita a pedido da africana Teodora da Cunha Dias. A recorrência ao negrito é para marcar as diferenças encontradas:

\begin{tabular}{|c|c|}
\hline $\begin{array}{l}\text { WISSENBACH (1988, p. 267) } \\
\text { Illmo Senhor Luiz da Cunha em }\end{array}$ & $\begin{array}{l}\text { OLIVEIRA (no prelo, p. 18-19) } \\
\text { Illmo Senhor Luiz da Cunha em }\end{array}$ \\
\hline $\begin{array}{l}\text { São Paulo } 20 \text { de otu... de } 1866 \\
\text { Eu hei de tima muito que eta que [.] om [?] gozamdo } \\
\text { e a sua filicidade cme para mim dezeio noto bem para } \\
\text { mi fazer o favor de vi por o nata falla com migo } \\
\text { sem falta mi falta } 198 \text { mireis para minha } \\
\text { liberdade no mais mi mande a repota des } \\
\text { ta para o senhor demicianno na cidade de sol } \\
\text { crava sem falta no mais eu itou pagando } \\
\text { como huma icrava deste pader mavado } \\
\text { no mais a Deus a Deus a te hum dia que Deus } \\
\text { me ajunde com sua garça divina mizeicodia } \\
\text { no mais sou a sua mulhe }\end{array}$ & $\begin{array}{l}\text { São Paulo } 20 \text { de out... de } 18^{\wedge} \text {, } \\
\text { Eu es de tima muito qeu e ta que vom gorzamdo } \\
\text { e a sua filicidade como para mim dezeio noto bem para } \\
\text { mi fazer o fa vou de vi por o nata falla com migo } \\
\text { sem falta mi falta } 198 \text { mireis para minha } \\
\text { li ber dade no mais mi mamde a repota des } \\
\text { ta para o senhor de mi cian no na ci da de de solr } \\
\text { cra va sen falta no mais eu i tou pagamdo } \\
\text { como huma i crava deste pader ma vado } \\
\text { no mais a Deus a Deus a te hum dia que Deus } \\
\text { no a jun de com sua garça devima mizeicode } \\
\text { no mais sou a sua mulhe }\end{array}$ \\
\hline tiodora da cunha dia & ti a do ra da cunha dia \\
\hline $\begin{array}{l}\text { Illmo Senhor Luiz dia } \\
\text { da cunha cera itegue } \\
\text { para o icravo do senhor } \\
\text { joão dia da cunha na ci } \\
\text { dade da limmera }\end{array}$ & $\begin{array}{l}\text { Illmo Senhor Luiz dia } \\
\text { da cunha cera i tegue } \\
\text { para o i cravo do senhor } \\
\text { João dia da cunha na ci } \\
\text { da de da lin nera }\end{array}$ \\
\hline
\end{tabular}


OLIVEIRA - Ajuntamento de fontes para a história...

Quem nessa vida não encontrou uma pedra no meio do caminho? Se conseguiu afastá-la pedindo a ajuda de um santo, nada custa dar-lhe um "agradinho" como retribuição. Pode ser uma fotografia, uma vela, uma mecha de cabelo e até um bilhete ou uma carta. Todo esse manancial de objetos referidos constitui diferentes formas de ex-votos. Dessa maneira, define-se um ex-voto como uma doação de objetos, dos mais variados tipos, aos santos julgados interventores na resolução de situações aflitivas que permeiam os vários campos da vivência humana.

Um tipo de ex-voto bastante peculiar, que agora se apresenta, são as chamadas tábuas votivas $^{1}$, que se diferenciam dos demais por apresentar, no mesmo espaço, no mesmo endereço, imagem e texto. Os elementos constitutivos desse tipo de prática votiva se organizam em três faixas horizontais, dispostas da seguinte maneira: no terço inferior exibe-se uma legenda contendo o nome da entidade milagrosa, do milagrado, a descrição da circunstância aflitiva e a data em que aconteceu o milagre; no terço médio aparece a figura do agraciado, às vezes deitado em leito com postura pré-mortuária, ocupando a parte central do ambiente singelo (em geral um quarto), despojado de mobiliário, característica usual nos séculos XVIII e XIX e com a rara presença de alguns familiares e médicos; na faixa superior, espaço nobre e

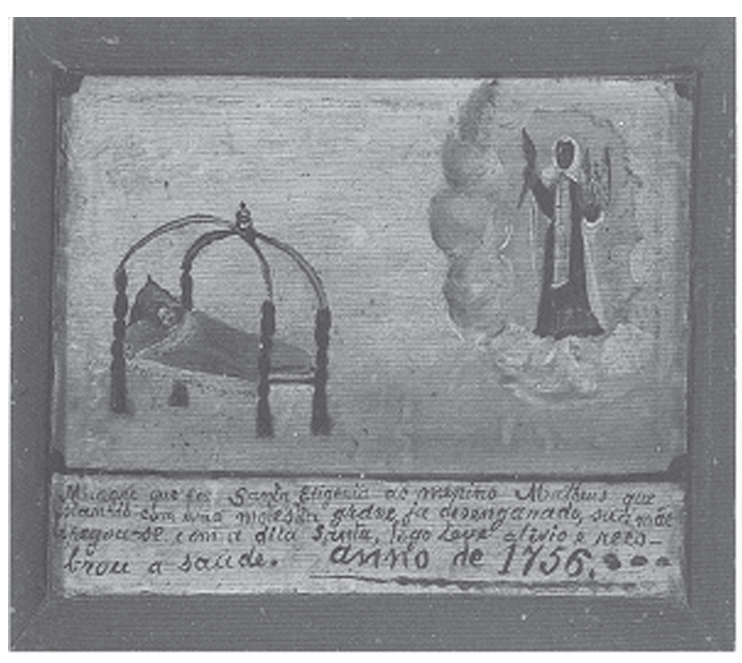

Figura 4: Tábua votiva do ano de 1756 Catálogo Castro (1994: 29) privilegiado, apresenta-se a divindade ou o santo milagroso entre nuvens ou envolto em raios, à direita ou à esquerda (Pessôa, 2001, p. 33). Quanto ao tema, expõe-se uma tábua votiva referente a doenças, mas é bom que se traga a afirmação de que as tabuinhas acolhem conteúdos bastante variados e que perpassam por inúmeras instâncias da vida humana.

Para uma reconstituição, em perspectiva histórica, do português popular brasileiro, tendo como objeto de análise as tábuas votivas, é evidente que o único elemento de relevância diz respeito à sua parte escrita, a legenda. A literatura sobre o tema é uníssona em afirmar que os denominados 'riscadores de milagres', em sua grande maioria, se enquadram no âmbito das classes populares ou subalternas. No Estado de Minas Gerais, Frota (1981, p. 45) assinala que a maior parte dos artífices coloniais a serviço das irmandades era composta por negros e mestiços, que viam nos ofícios mecânicos, desprezados pela elite, uma possibilidade de ascensão social. Quanto ao parecer de Castro (1979, p. 112), a observação

${ }^{1}$ Tábuas votivas, tábuas, tabuinhas, quadros, quadros pintados, quadrinhos, quadrinhos pintados são tomados como sinônimos neste trabalho, porque dessa maneira procede a bibliografia sobre o tema. 
da perspectiva e da ortografia, que, geralmente, se apresentam "erradas", já é o bastante para a construção da imagem do riscador de milagres como um "curioso", pintor de ocasião, que reside sempre às margens, e procurado apenas em casos de necessidade.

Quando se tenta formar uma série composta de ex-votos pintados para estudos de naturezas várias, os empecilhos podem vir de todos os lados; as dificuldades aumentam, no entanto, quando o foco do estudo é de caráter lingüístico, porque, como já se disse, só as legendas são de serventia. Essa parte constitutiva das tabuinhas, de modo geral, se perdeu no tempo por várias razões. Segundo Castro (1979, p. 111), tanto no Brasil quanto em Portugal, os estragos do tempo contribuíram para seu desaparecimento. Em alguns casos, o modo de produção da legenda também deu a sua parte para que se desgastasse com o devir do tempo: confeccionadas em papel e coladas sobre os quadrinhos pintados, na parte inferior, a

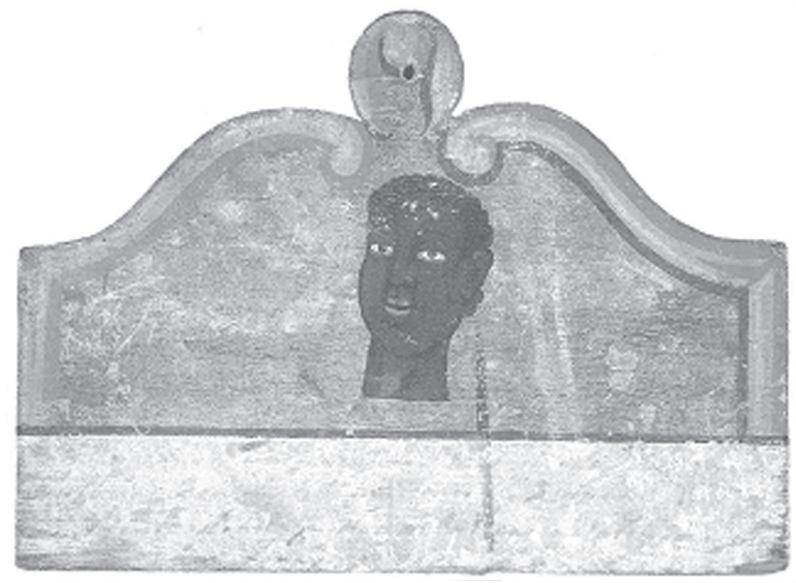

Figura 5: Tábua votiva com legenda apagada Coleção Museu de Arte Sacra de Angra dos Reis fragilidade do material só fez acelerar o seu apagamento. Cabe aqui um exemplo: Pessôa (2001, p. 41-141) reuniu em um catálogo 117 tábuas votivas que, hoje, pertencem ao acervo do Museu de Arte Sacra de Angra dos Reis, no Estado do Rio de Janeiro, no entanto apenas 34, o que representa 29.0\% do total geral, apresentam a parte escrita e, mesmo assim, há exemplares que exibem longos trechos ilegíveis. Entra em cena também a própria orientação da Igreja Católica que, considerando os quadros pintados produtos imperfeitos e, conseqüentemente, condenando que a eles se reservasse um espaço em recintos sagrados, os levou a se constituir em material merecedor de queimas. Não se pode deixar de lado, como mais uma causa para a escassez das tabuinhas, o advento da fotografia e da produção industrial de peças de gesso. Desse último aspecto deriva o fato de que, ao andarem juntos a raridade da confecção desse tipo de prática votiva e o valor comercial que por conta disso foi adquirindo, muitos dos quadrinhos pintados foram parar em mãos de colecionadores.

\section{CARTAS DE CANGACEIROS}

Uma manifestação típica de banditismo no Brasil teve endereço e tempo certos: o sertão nordestino e o arco temporal que vai de 1900, com a prisão de Antônio Silvino, a 1940, com o assassinato de Cristino Gomes da Silva, o Curisco. Está-se a referir ao cangaço que, na região do Nordeste brasileiro, só não deu a conhecer os seus atos de crueldades, 
OLIVEIRA - Ajuntamento de fontes para a história...

roubos, assassinatos, extorsões a dois estados: Piauí e Maranhão; os demais "sentiram na pele", em maior ou menor grau, as ações dos cangaceiros.

A rede de relações movimentada pelo cangaço articulava gentes localizadas em várias instâncias sociais, mas que, de modo geral, pode se resumir no triângulo cangaceiroscoiteiros-policiais. Os cangaceiros eram os malfeitores e muitos deles se tornaram célebres, porém nenhum "chegou aos pés" de Lampião, o mais afamado, o mais procurado, o mais ardiloso de todos eles. Em outro vértice, estão os denominados coiteiros. Tinha esse epíteto o sertanejo que abrigava e protegia os cangaceiros. Segundo Nascimento (1998, p. 26), existiam coiteiros por sugestão, ou imitação, simpatizantes ou admiradores dos membros do banditismo, porque frutos do mesmo meio social. Houve ainda, de acordo com o autor referido, os coiteiros por interesse, traficantes do crime, cúmplices do cálculo, que davam a mão aos cangaceiros, objetivando lucros e vantagens. Por outro lado, marcaram também a sua presença na rede dos coiteiros aqueles que, vendo o acaso a que eram submetidos pelas autoridades legais, ajudavam os bandidos para não perderem a vida ou a propriedade. As forças formadas por soldados para combater essa manifestação de banditismo eram chamadas de "volantes", porém "macacos" para os cangaceiros. Foram criadas para rápida atuação, isto é, perseguir os bandidos e acabar, de pronto, com o cangaço. Acontece que Nascimento (1998, p. 32) mostrou que as volantes não passavam de patrulhas com mobilidade restrita dentro da caatinga, porque compostas por soldados, na sua grande maioria, despreparados e por serem precárias as condições instrumentais para a execução da tarefa a que estavam destinados.

A oralidade tinha papel importante dentro da rede social tecida pelo cangaço. Ocorreu, todavia, que também desencadeou escrituras de naturezas diversas: cartas, bilhetes, telegramas, orações, acordos governamentais, relatórios, literatura etc. Interessam, principalmente, as duas primeiras tipologias, porque, em sua quase totalidade, saíram das mãos dos próprios integrantes do cangaço.

A escrita, na esfera dessa manifestação, tinha diversas funções - extorquir, alertar, ameaçar, agradecer, acalmar e, abaixo, 2 exemplos que ilustram algumas das intenções de que se falou acima: o primeiro documento é uma carta, datada do ano de 1926, que revela o descontentamento de Lampião com o coronel Veremundo Soares:

Senhor Verimundo Suaris

Suas Saudações,

O fim desta somente para saber Qual seu plano. Qui apois, Em minha paçagem O Senhor mandou, Uma força a ir, atras, d'eu mesmo. Pelerehou, Bastante di mim. Em outra oura nois Já fumos, Inimigo porem para opresente, Eu pençava Que nois hera, Amigo, para Senhor Eu Era mais para si mi Pareci Qui O Senhor Era meu Inimigo, portanto Eu 1hi faço Esta, para Saber qual E seu Destino. Ja mandei avizar ao Padri Ciciro, Qui Nesta minha diligença Qui si Alteroci contra mim foi, o município di Salguero, tenha muita cautela Eu não volte para U mesmo Qui Eu era outas óra, Eu Bem Qui quéro virar Santo e faser a felicidadi para Voceis mesmo sem mais asunto.

Capitam Virgulino Ferreira 
Já neste segundo, o rei do cangaço, também no ano de 1926 e em tom de ameaça, escreve ao coronel Horácio Ferraz exigindo que lhe mande, por bem ou por mal, certa quantia em dinheiro:

\section{Illustríssimo Senhor Horácio Ferraz,}

Estimo suas saudações com toda Excelentíssima familia. Ofim desta para lhe pedir-lhe Um conto di réis. Espero Qui o Senhor não faça duvida. Será isto Melhor do Qui Vossa mercê ter outro Priguiso mais alem. Espero Qui Reposte logo, agora alarmi as autoridade, i depois não si sahia mal. Sem mais Asunto, Reposta Urgente.

\section{Capitam Virgulino Ferreira da Silva}

Vulgo Lampião

Houve vozes que se manifestaram no sentido de acusar o analfabetismo que assolava o Nordeste como uma das molas propulsoras para a emergência de crendices e de alguns males sociais. Os censos realizados para os Estados nordestinos - o de 1900, de 1920 e de 1940 - descortinam o fato de que o analfabetismo, de fato, reinava na região, uma vez que, nos três censos analisados, o número de letrados permanece em torno de $20.0 \%$, talvez por isso Nascimento (1998, p. 29) afirma que, ao adotar Lampião o banditismo como profissão, passou a conviver com homens marginalizados, condenados pela lei, além de ignorantes e analfabetos.

Quanto ao último rótulo empregado, ele não é de todo verdade. Sem dúvidas, o cangaço deve ter acolhido em seu seio muitos indivíduos com o perfil de Volta-Seca, definido por Mello (2004, p. 129) como analfabeto, profundamente inculto e limitado. Porém esse mesmo estudioso do tema traz informações que relativizam o que diz Nascimento (1998, p. 29) sobre a predominância da carência das letras nas teias do cangaço. A respeito do líder maior, Lampião, sabe-se que frequientou as aulas de primeiras letras e mantinha um gosto pela leitura e pela escrita. Outros cangaceiros, para além dele, tinham, para mais ou para menos, a faculdade das letras. É o caso, por exemplo, de José Leite de Santana, o Jararaca, que é descrito como cafuzo, olhos agateados, boa estatura, bem-proporcionado e alfabetizado (Mello, 2004, p. 215-254).

Como já se aludiu anteriormente, os documentos redigidos na esfera do cangaço

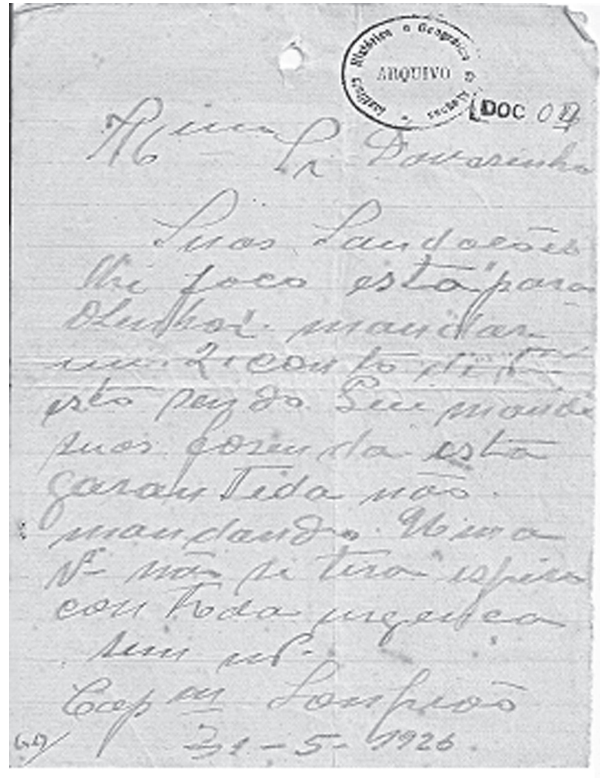

Figura 6: Carta de Lampião - 31.05.1826 Instituto Histórico e Geográfico de Alagoas 
OLIVEIRA - Ajuntamento de fontes para a história...

por diversos dos seus componentes provêm de vários fundos documentais, mas, por ora, a atenção só será dirigida aos textos escritos por Lampião, que carregam em si algumas questões relativas a problemas que surgem quando da sua edição. Em primeiro lugar é preciso familiarizar-se com a execução caligráfica do cangaceiro-mor. Se assim não o fizer, pode o editor cair numa cilada: atribuir a Lampião documentos que foram escritos como expressão da sua vontade, mas que não saíram de seu próprio punho. Conseguiu-se amealhar 25 documentos em nome de Virgulino Ferreira da Silva, porém, em 4 deles, o cangaceiro foi apenas o mentor intelectual e não material.

Mello (2004, p. 401-408) apresenta, como apêndice do seu livro Guerreiros do sol. Violência e banditismo no Nordeste do Brasil, transcrição de boa parte das cartas de Lampião. Editadas estão elas também no acervo da Sociedade Cabras de Lampião, com uma vantagem, porém: acompanham-nas os originais com os quais se pode fazer leitura própria. Ocorre que Lampião, desaforado que era, deixou para a polícia sergipana, no dia $25 \mathrm{de}$ novembro de 1929, um recado grafado a lápis numa parede de bilhar na cidade de Capela. Desencontros de transcrição dessa mensagem se apresentam aos montes na versão do documento apresentado pela Associação Cabras de Lampião e por Mello (2004, p. 406), como se pode avistar no quadro abaixo:

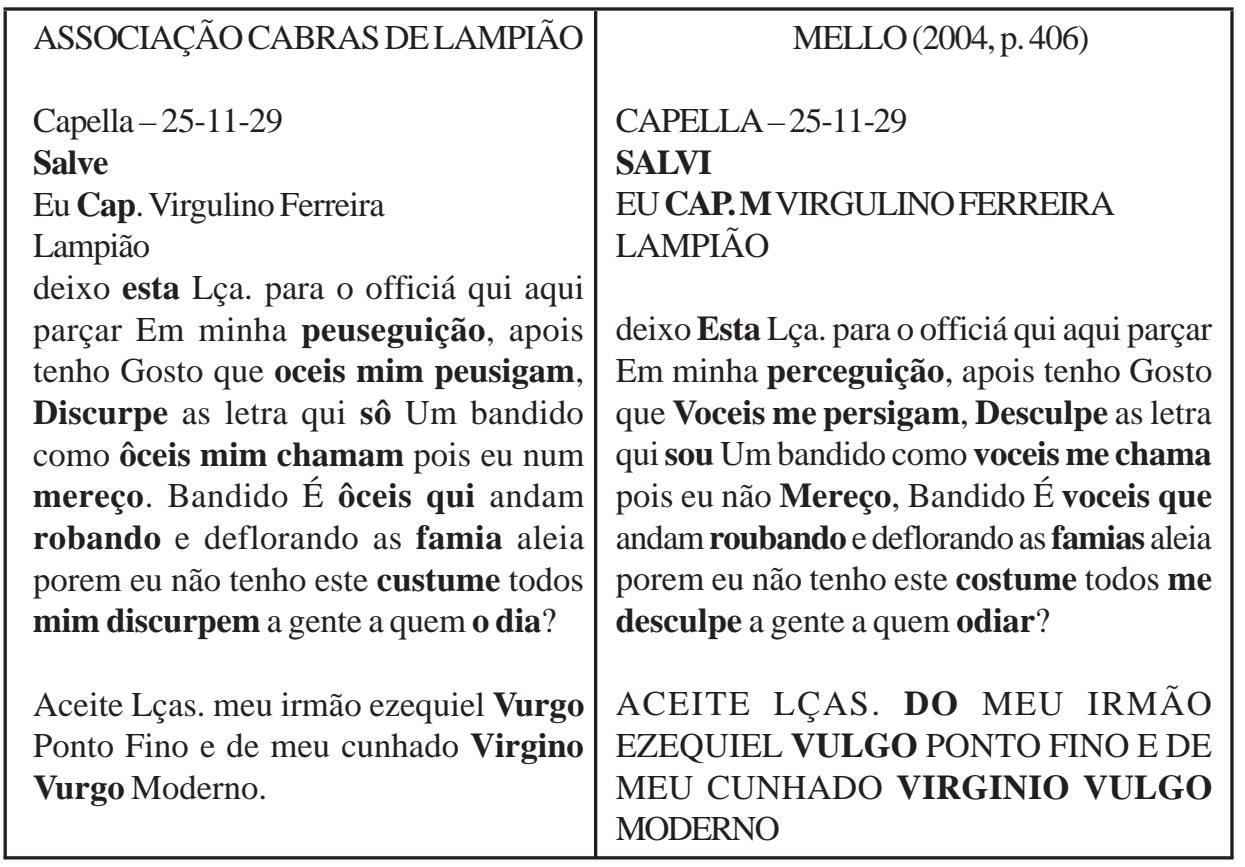

Atendo-se tão-somente aos fenômenos circunscritos na esfera da fonética/fonologia, a edição efetuada pela Associação Cabras de Lampião se apresenta como aquela que, em maior número, deixou que marcas fônicas da fala se transpusessem para a escrita. Ocorre, entretanto, que, conjuntamente analisados os 21 textos inequivocadamente escritos por 
Cadernos de Estudos Lingüísticos 50(2) - Jul./Dez. 2008

Lampião, os resultados mostram que não é o seu forte a aférese da consoante [v] no vocábulo você (ôceis por voceis) e nem a vocalização de /r/ em posição de coda (peuseguição por perceguição), pelo que pode ser esse um indício, mesmo que pálido, a depor que a edição de Mello, já citado, talvez esteja mais próxima do que teria sido a mensagem original, mas a certeza por inteira, essa não há.

\section{CONSIDERAÇÕES FINAIS}

As palavras foram alongadas, contudo, através delas, vê-se, por assim dizer, uma 'vitória' : é possível, sim, encontrar produtos gráficos executados por indivíduos pertencentes a classes subalternas, o que sugere, de certo modo, que a escrita no Brasil, ao longo de sua história, teve um alcance um pouquinho mais lato. Mas a procura por essas manifestações gráficas encontra dificuldades que começam, desde logo, com possíveis lugares onde se possam localizá-las. Nessa direção, a empreitada não pode prescindir de diálogos a serem empreendidos com outras áreas do conhecimento humano e, além do mais, há de se estar disposto para dar de frente com o que Petrucci (1999) designou de 'dispersão arquivística', ou seja, empreender uma 'caçada' que, por vezes, se enviesa, se bifurca em diversas direções. Que venham também produtos gráficos redigidos por grupos sociais subalternos, de alguma forma atingidos pelo quociente de durabilidade, que resultam em textos danificados, corrompidos, de difícil leitura. Isso sem mencionar problemas de outras naturezas: a dicotomia autor intelectual/autor material, dificuldades em se estabelecer uma edição dos documentos quando faltantes os originais etc; mas "se a alma não é pequena, tudo vale a pena".

\section{REFERÊNCIAS BIBLIOGRÁFICAS}

CASTRO, Márcia de Moura. (1979). O ex-voto em Minas Gerais e suas origens. Cultura, n. 31. p. 100112 .

(1994). Ex-votos mineiros: as tábuas votivas no ciclo do ouro. Rio de Janeiro: Expressão e Cultura.

FAUSTO, Boris. (1994). História do Brasil. São Paulo: EDUSP/FDE.

FROTA, Leila Coelho. (1981). Promessa e milagre nas representações coletivas de ritual católico, com ênfase sobre as tábuas pintadas de Congonhas do Campo, Minas Gerais. In: PROMESSA E MILAGRE NO SANTUÁRIO DO BOM JESUS DE MATOSINHOS, CONGONHAS - MINAS GERAIS. Brasília: Fundação Nacional Pró-Memória. p. 17-53.

GINZBURG, Carlo. (1989). Sinais: raízes de um paradigma indiciário. In: Mitos, emblemas, sinais. Morfologia e história. 2 ed. São Paulo: Companhia das Letras. p. 143-179.

HOUAISS, Antônio. (1992[1984]). O português no Brasil. 3 ed. Rio de Janeiro: UNIBRADE/UNESCO/ UERJ.

MATTOS E SILVA, Rosa Virgínia. (2002). Para a história do português culto e popular brasileiro: sugestões para uma pauta de pesquisa. In: ALKMIM, Tânia Maria (Org.). Para a história do português brasileiro. Volume III: novos estudos. São Paulo: Humanitas. p. 443-464. 
OLIVEIRA - Ajuntamento de fontes para a história...

MELLO, Frederico Pernambucano de. (2004). Guerreiros do sol. Violência e banditismo no Nordeste do Brasil. São Paulo: A Girafa.

NASCIMENTO, José Anderson. (1998). Cangaceiros, coiteiros e volantes. São Paulo: Ícone.

OLIVEIRA, Klebson (no prelo). As tábuas votivas: mais uma fonte para a história do nosso "latim vulgar". Signos lingüísticos, n. 3, México, Universidad Autónoma Metropolitana - Iztapalapa. . (2004). E agora, com a escrita, os escravos! In: COSTA, Sônia Bastos Borba; MACHADO FILHO, Américo V. Lopes (Orgs.). Do português arcaico ao português brasileiro. Salvador: EDUFBA. p. 139-162.

. (2006). Negros e escrita no Brasil do século XIX: sócio-história, edição filológica de documentos e estudo lingüístico. Tese de Doutorado. 3 v. Salvador: Programa de Pós-graduação em Letras e Lingüística da UFBA.

PESSÔA, José. (2001). Milagres: os ex-votos de Angra dos Reis. Rio de Janeiro: Casa da Palavra.

PETRUCCI, Armando. (1999). Para La historia del alfabetismo y de la cultura escrita: métodos, materiales y problemas. In: Alfabetismo, escritura, sociedad. Barcelona: Gedisa. p. 25-39.

REIS, João José. (1997). Identidade e diversidade étnicas nas irmandades no tempo da escravidão. Tempo, Rio de Janeiro, v. 2, n. 3. p. 7-33.

SCARANO, Julita. (1978). Devoção e escravidão. A Irmandade de Nossa Senhora do Rosário dos Pretos no Distrito Diamantino no século XVIII. 2 ed. São Paulo: Nacional.

WISSENBACH, Maria Cristina Cortez. (1998). Sonhos africanos, vivências ladinas. Escravos e forros em São Paulo (1850-1880). São Paulo: Hucitec. 